\title{
BMJ Open Pattern and spectrum of tornado injury and its geographical information system distribution in Yancheng, China: a cross-sectional study
}

Qiangyu Deng, Yipeng Lv, Chen Xue, Peng Kang, Junqiang Dong, Lulu Zhang

To cite: Deng Q, Lv Y, Xue C et al. Pattern and spectrum of tornado injury and its geographical information system distribution in Yancheng, China: a crosssectional study. BMJ Open 2018;8:e021552. doi:10.1136/ bmjopen-2018-021552

- Prepublication history for this paper is available online. To view these files, please visit the journal online (http://dx.doi org/10.1136/bmjopen-2018021552).

$\mathrm{QD}, \mathrm{YL}$ and $\mathrm{CX}$ contributed equally.

Received 8 January 2018 Revised 7 April 2018 Accepted 15 May 2018

\section{Check for updates}

Department of Military Health Service Management, College of Health Service, Second Military Medical University, Shanghai, China

Correspondence to Professor Lulu Zhang; zllrmit@aliyun.com

\section{ABSTRACT}

Objectives Few studies of tornado injuries have considered differences related to damage levels and Enhanced-Fujita (EF) scale ratings. This study aimed to evaluate the pattern, spectrum and geographical distribution of injuries related to the Yancheng tornado and provide guidelines for effective emergency medical strategies.

Setting The study was conducted at three hospitals which treated patients with injuries related to the tornado in Yancheng, China.

Participants We obtained the records of 451 patients with tornado-related injuries. Of these, 401 valid trauma medical records were included; 50 other records were excluded for insufficient information. Informed consent was obtained from all patients by telephone.

Main outcome measures We analysed patients' injury sites and types and used the abbreviated injury scale (AIS) to standardise injury severity. Geographical information system and non-parametric tests were used to analyse the effects of geographical factors on casualties.

Results Women, middle-aged/elderly individuals (age $>45$ years) and children/adolescents $(<18$ years) accounted for $51.62 \%, 77.30 \%$ and $12.47 \%$ of injured patients, respectively. This caused a dumbbell-shaped age distribution. Head (46.63\%), body surface (39.90\%) and lower-limb (29.43\%) injuries were common, as were soft-tissue injuries $(90.77 \%)$, fractures $(38.90 \%)$ and organ damage (19.70\%). Minor injuries (AIS=1) were common $(60.85 \%)$, whereas critical/fatal injuries (AIS $\geq 5$ ) were very rare $(2.50 \%)$. Although the densities of injury varied among damage levels and EF ratings for different areas, areawise differences in injury severity (AIS scores) were not significant $(p>0.05)$.

Conclusion We recommend the use of helmets to prevent head injuries caused by tornadoes and suggest prioritising the treatment of high-risk head and multiple-organ injuries. Additionally, medical rescuers should follow the 'same quality and different quantity' principle: the injured in all affected areas should receive equal attention, but numbers of medical personnel should be allocated based on the level of effects from the tornado.

\section{INTRODUCTION}

Tornadoes are deadly storms that often result in significant casualties. ${ }^{12}$ At 14:30 on 23 June
Strengths and limitations of this study

- This is the first geographical information system-based study to evaluate tornado injury characteristics among areas with different damage and Enhanced-Fujita scale ratings in China.

- Medical records of tornado patients were collected integrally from three hospitals.

- The pattern and spectrum of tornado injuries were studied according to injury site, injury type and injury severity (abbreviated injury scale).

- Further studies should include larger samples of tornado patients.

- More detailed meteorology and building data will yield better results.

2016, a devastating tornado killed 99 people and injured 846 more in Yancheng, eastern China $^{3}$ in the deadliest tornado disaster in China in nearly half a century. The China Meteorological Administration rated the storm as a 4 on the Enhanced-Fujita (EF) scale, with a maximum wind speed surpassing $266 \mathrm{~km} /$ hour. $^{4}$ Although the incidence of tornadoes in China cannot be compared with that in the USA, the former recorded a total of 2210 tornadoes responsible for killing 2000 people and injuring 30000 during a 30-year period from 1984 to $2013 .{ }^{5}$ In China, tornadoes occur primarily in developed coastal provinces with higher population densities and degrees of economic development, which leads to a substantial risk for serious damage and losses of life. ${ }^{6}$

To date, tornado research has primarily been conducted in the USA, and the impacts of tornadoes on public health (eg, injury) has drawn increasing attention. ${ }^{7}$ Some studies of the characteristics of tornado injuries ${ }^{89}$ have identified soft-tissue, head and limb injuries as the most common types. However, these studies did not apply a standardised injury severity scoring method, despite the 
availability of updated and standardised versions of traumatic injury analysis methods (ie, recording injury sites, types and severity) ${ }^{7}$ and the abbreviated injury scale (AIS).${ }^{10}$ As an understanding of the pattern and spectrum of tornado-related injuries can improve the efficiency of rescue efforts, standardisation of the methods used to report these injuries is an urgent matter.

Importantly, the geographical information system (GIS) has been widely used to aid disaster rescue efforts. ${ }^{11}{ }^{12}$ Peek-Asa $e t$ al used such technology to analyse injuries resulting from the 1994 Northridge Earthquake with regard to the distance from the earthquake epicentre, Modified Mercalli Intensity Index, peak ground acceleration and proportion of damaged buildings. ${ }^{13}$ Furthermore, Curtis et al used GIS technology to assess the distribution of medical needs in the Los Angeles area after an earthquake. ${ }^{14}$ In general, the lethality of a tornado is clearly related to geographical characteristics such as the size of and wind level within the area of damage ${ }^{1516}$ as well as emergency medical rescue efforts. Specifically, the risk of injury or death increases with increasing wind speed or intensity and decreases with increasing distance from the tornado. For example, Simmons and Sutter analysed tornado data collected by the United States National Weather Service from 1950 to 2007 and concluded that $62 \%$ of tornado-related deaths in that country resulted from tornadoes with rankings of 4 or 5 on the Fujita (F) scale. ${ }^{17}$ Additionally, Fricker et al demonstrated that the rate of tornado casualties increased by $33 \%$ per doubling of tornado energy. ${ }^{18}$

Currently, tornado severity is evaluated using the EF scale, which was based on the $1971 \mathrm{~F}$ scale and revised in 2007. ${ }^{15} 19$ The EF-scale ranges from 0 to 5 , with 5 indicating the highest severity. Some studies have comprehensively assessed the proportion of damaged buildings and other factors to rate different damage areas. ${ }^{415}$ However, it is difficult to rate storms using either the EF-scale or damage areas within the affected region because both methods require meteorological radar data, groundbased instrumental observations and information about property losses and other field investigations. Therefore, studies of tornado-related injuries rarely employ GIS data.

Although several studies have presented data regarding injuries in different areas, they did not explore the interactions between them. Paul and Stimers studied the distributions of 162 deaths in different damage areas caused by the Joplin, MO tornado, ${ }^{15}$ while Curtis and Fagan used a spatial video of damage assessments to analyse the distribution of 135 tornado-related deaths. ${ }^{20}$ Ashley provided spatial and temporal analyses of tornado fatalities in the USA from 1880 to $2005,{ }^{1}$ while Shen and Hwang provided a spatial risk analysis of tornado injuries and fatalities in the same country. ${ }^{21}$ Fricker et al reported a method for the spatial apportioning of tornado casualties ${ }^{2}$ and, more recently, evaluated the effects of tornado energy has on related casualties. ${ }^{18}$ Both Simmons and Sutter ${ }^{17}$ and Lim $e t$ $a l^{22}$ analysed tornado-related deaths in the USA based on F scale ranking. By contrast, no studies have reported the spatial distribution of tornado-related injuries in China. However, injury characteristics, especially severity, have an important impact on outcomes, and injuries of different severities have different requirements for timely treatment in different areas. Therefore, an understanding of the geographical distribution of tornado-related injuries is helpful for developing timely and effective emergency medical rescue strategies. It is thus necessary to evaluate the distribution of tornado-related injuries according to the tornado damage area and severity (EF-scale).

The present study had three aims. First, we aimed to study the characteristics of tornado-related injuries, including site, type and severity and to compare these with the injury characteristics recorded for other disasters and tornadoes in the USA. Second, we aimed to study the spatial distribution of tornado-related injuries in Yancheng. Third, we aimed to analyse the differences in AIS scores among different damage and EF-scale areas. This research will help us to understand the characteristics of tornado-related injuries and provide a reference for both predicting potential medical needs in different geographical regions and improving medical rescue strategies.

\section{MATERIALS AND METHODS}

\section{Patient and public involvement}

We collected medical records from the three hospitals in Yancheng that treated most tornado patients following the tornado on 23 June: Funing County People's Hospital, Jianhu County People's Hospital and Yancheng Third People's Hospital. These three hospitals received $53.31 \%$ of all patients injured in the tornado $(451 / 846)$; the remaining injured patients were scattered among 16 other hospitals located at greater distances. Of the studied hospitals, most of the injured were treated at or referred by Funing County People's Hospital, which was the nearest to the disaster area. Jianhu County People's Hospital was the second nearest to the disaster area. Yancheng Third People's Hospital, which is located in the urban centre of Yancheng and affiliated with a tertiary hospital (highest Chinese hospital level), admitted a large number of severely injured tornado patients who were referred by lower-level hospitals. Patients included in the study were those who had been directly injured as a result of the tornado and whose location during the tornado could be identified. Patients with recurrent chronic disease or stress-related conditions due to the tornado but no trauma were excluded.

Unified medical record collection forms were developed, and data extraction was independently performed by two investigators and proofread for inconsistent entries. Three types of information were extracted: (1) demographic information, including age, sex, marriage status and occupation; (2) trauma information, including the cause of injury, prehospital time, length of hospitalisation and injury site, type and severity and (3) location during the tornado. Injury site was categorised based 
on the body region affected ${ }^{23} 24$ and included the head, neck, face, chest, spine, abdomen/internal organs, upper extremities, lower extremities/pelvis and body surface/ other. Injury severity was judged by clinical experts using the 2005 version of the AIS scale; the AIS scores range from 1 (minor injury) to 6 (fatal injury). For patients with multiple injuries, only the most severely injured site was considered in the final AIS score. ${ }^{23-25}$

The investigators were master's degree students in Social Medicine and Public Health Service Management. Prior to data collection, the investigators received training to familiarise themselves with the medical record structure and research guide. Four investigators visited the three hospitals during 12-30 July 2016 (1 month after the tornado). A total of 451 records of patients injured in the tornado were obtained. Of these, 50 records were excluded for not mentioning the location of the injured person during the tornado. Finally, $401(88.91 \%)$ valid trauma medical records were included in the analysis.

\section{GIS data analysis}

The China National Disaster Reduction Centre and Chinese Academy of Sciences conducted a detailed study of the 23 June Yancheng tornado. They classified the disaster area into four categories (disaster-affected area, general area, severe area and very severe area) based on six factors, including the number of deaths, injuries, emergency relocations, employment of disaster relief staff and direct economic losses. ${ }^{4}$ A team led by Professor Zhiyong Meng from Peking University conducted an accurate survey of the 23 June Yancheng tornado and classified areas as EF0-EF4 based on an in-the-field investigation, aerial image data, ground weather station information and radar data.

Based on the above research, Arcview V.10.3 software (Redlands, California, USA) was used to vectorise the geographic image data, which included four types of damage areas and EF0-EF4 areas. The results were added to the China Online Street Warm map in ArcGIS Online. A data comparison test revealed that the level of precision was sufficient to meet the demands of analysis. Based on the geographic locations listed in medical records, the injured patients were located individually on the map and their locations were matched to the damage and EF-scale areas. If the locations of multiple wounded patients were extremely close on the map, they were aggregated into a single point for clarity and the number of wounded was marked near the point. However, this did not alter the recorded locations of the wounded in different damage areas or the related statistical analysis.

\section{Statistical analysis}

Patient age, prehospital time and length of hospitalisation were converted into categorical variables. The demographic information and trauma characteristics were subjected to a descriptive analysis. The number of injured patients, area size and densities of injured patients in different damage and EF-scale areas were analysed

\begin{tabular}{llcc} 
Table 1 & Demographic characteristics of the injured \\
\hline Items & Groups & Number & Percentage (\%) \\
\hline Sex & Male & 194 & 48.38 \\
Age (years) & Female & 207 & 51.62 \\
& $18-29$ & 50 & 12.47 \\
& $30-44$ & 23 & 4.49 \\
& $45-64$ & 124 & 5.74 \\
\multirow{4}{*}{ Marriage } & Married & 368 & 30.92 \\
& Unmarried & 33 & 46.38 \\
\multirow{4}{*}{ Occupation } & Farmer & 327 & 91.77 \\
& Student & 40 & 81.23 \\
& Worker & 11 & 9.98 \\
& Others & 23 & 2.74 \\
\hline
\end{tabular}

using the GIS. Non-parametric tests were performed to determine the effects of geographical characteristics on the AIS scores. SPSS V.21.0 (SPSS, Chicago, Illinois, USA) was used for the statistical analyses. All tests were two-tailed, and a $\mathrm{p}<0.05$ was considered to indicate statistical significance.

\section{Ethical statement}

Access to medical records was approved by the three participating hospitals and all patients. Informed consent was obtained from the participants by telephone. For injured patients aged $<18$ years, consent was given by the legal guardians.

\section{RESULTS}

\section{Demographic characteristics}

Of the injured patients, $51.62 \%$ were women and $77.30 \%$ were middle-aged or elderly (age $>45$ years). Additionally, $91.77 \%$ were married and $81.55 \%$ were employed as farmers (table 1).

\section{Injury characteristics and standardised scores}

Of the injuries, $60.10 \%$ were attributed to the collapse of a building. Furthermore, $63.09 \%$ of injured patients received hospital treatment within 12 hours and $58.61 \%$ had a hospitalisation length of $\leq 2$ weeks (table 2 ).

Of the nine injury sites, the head, body surface and upper extremities were most frequently affected, followed by the chest. Most patients had multiple injuries and seven patients had five injury sites (table 2).

Skin and soft tissue injuries, fractures and organ injuries were most frequently reported. The number of fractures was counted for each of the nine injury sites defined; accordingly, multiple fractures at the same injury site were recorded as a single fracture. Single fracture was reported in $71.79 \%$ of affected patients, while two patients had four fractures. Bacterial infection and disturbance 
Open access

Table 2 Injury characteristics of the injured*

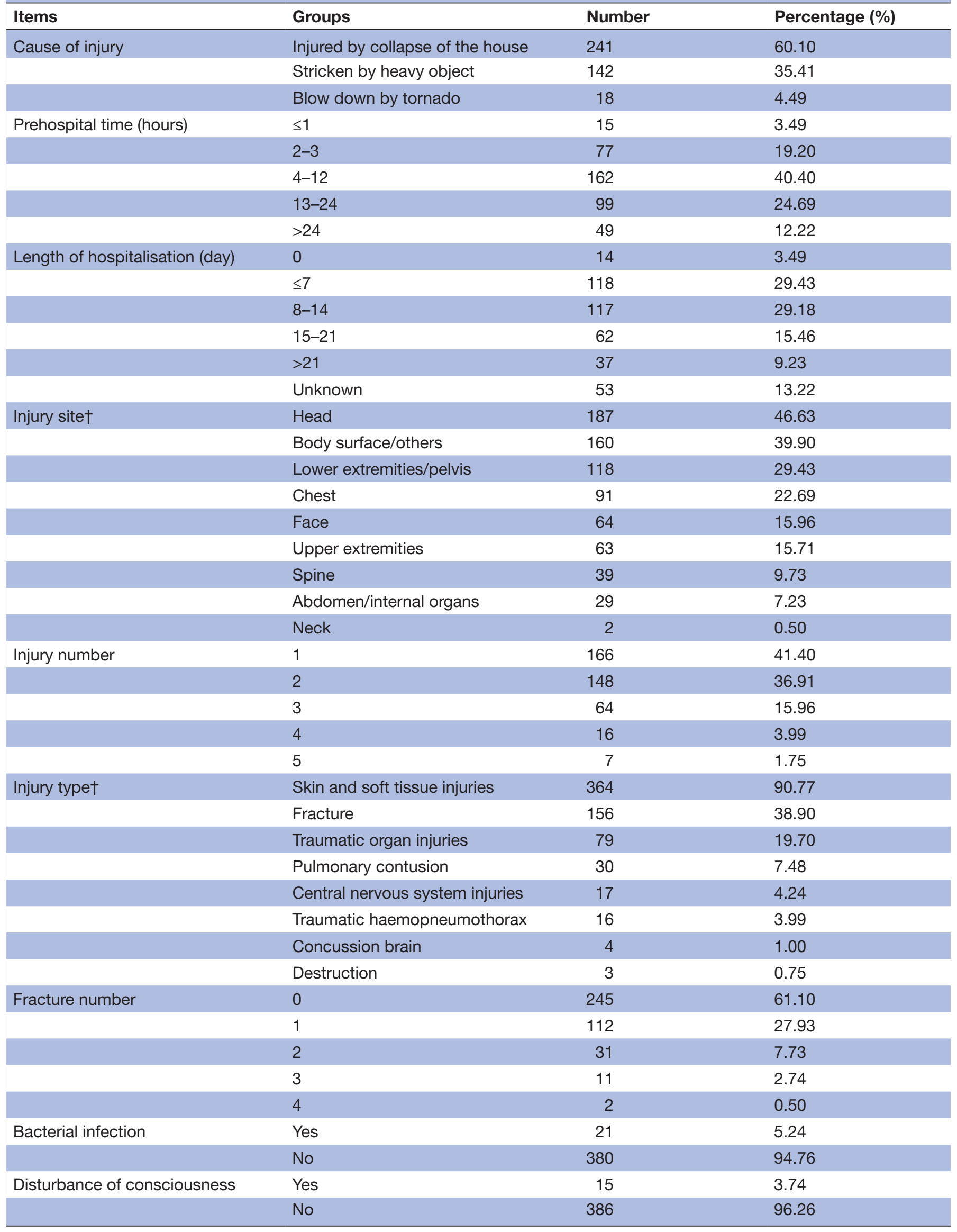

Continued 
Table 2 Continued

\begin{tabular}{llcl}
\hline Items & Groups & Number & Percentage (\%) \\
\hline AIS score & 1 (minor) & 244 & 60.85 \\
& 2 & 62 & 15.46 \\
& 3 & 58 & 14.46 \\
& 4 & 27 & 6.73 \\
& 5 & 7 & 1.75 \\
& 6 (fatal) & 3 & 0.75 \\
\hline
\end{tabular}

*This table contains all injury information, including all injury sites and types.

†The relative percentage of injury site and type indicate incidence rate.

AIS, abbreviated injury scale.

of consciousness occurred in $5.24 \%$ and $3.74 \%$ of the patients, respectively (table 2 ).

Regarding the severity of injury, $60.85 \%$ of patients sustained injuries with AIS scores of 1, while 2.50\% sustained injuries with AIS scores of $\geq 5$ (table 2). Regarding the distribution of AIS scores at different injury sites, all 10 patients with very severe injuries (AIS score $\geq 5$ ) had sustained injuries at high-risk sites, including the head in 7 patients, thorax in 2 patients and spine in 1 patient. Three patients with fatal injuries (AIS score $=6$ ) had sustained severe crush injuries to the head or chest and one died of a head injury consequent to medical failure (table 3).

\section{Distribution of injured patients in different areas}

Regarding different damage areas, only one casualty occurred in the general area; therefore, for analytical purposes, the general and severe areas were combined into a collective 'severe area'. The number of injured patients was lower in the disaster-affected area than in the areas of severe or very severe damage. Furthermore, the density of injured patients per square kilometre increased with increasing damage severity in the area, with the highest density reported in the very severe area (table 4 , figure 1).

Geographically, although the scope of the EF0-4 areas was smaller than that of the entire disaster-stricken area, the wind level classification of the former was more accurate. The density of injured patients increased with increasing wind levels, and the highest density was observed in the EF4 area. Given the immensity of the entire disaster-stricken area, Professor Meng could only conduct an in-field investigation of the area related to the centreline of the tornado. Accordingly, 154 patients who had reported locations outside of the EF-scale areas were not included in the analysis of EF-scale areas (table 4, figure 2).

\section{Injury severity in different areas}

We also conducted non-parametric tests to further evaluate the severity of injuries among different damage and EF-scale areas. These analyses demonstrated that the geographical characteristics had no significant effects on AIS scores $(p>0.05$; table 5$)$.

\section{DISCUSSION}

Demographic characteristics

The age distribution of injured patients had 'dumbbell shape', as $77.30 \%$ of injured victims were middleaged or elderly (age $>45$ years), $12.47 \%$ were children/ adolescents ( $<18$ years), while only $10.23 \%$ were young adults. By comparison, $38.69 \%$ of victims injured during the Oklahoma tornadoes of 1999 were aged $>45$ years ( $16.78 \%$ were aged $<15$ years) ${ }^{26}$ Studies on the Alabama tornadoes of 2001 showed that $49 \%$ of injury victims were older than 45 years. ${ }^{8}$ For other natural disasters such as earthquakes, the age distributions of the victims

Table 3 The distribution of AIS scores in different injury sites*

\begin{tabular}{|c|c|c|c|c|c|c|c|c|c|}
\hline $\begin{array}{l}\text { AIS } \\
\text { score }\end{array}$ & Head & Face & Neck & Chest & $\begin{array}{l}\text { Abdomen/internal } \\
\text { organs }\end{array}$ & Spine & $\begin{array}{l}\text { Upper } \\
\text { extremities }\end{array}$ & $\begin{array}{l}\text { Lower } \\
\text { extremities/pelvis }\end{array}$ & $\begin{array}{l}\text { Body surface/ } \\
\text { others }\end{array}$ \\
\hline 1 & 70 (28.69) & $32(13.11)$ & $1(0.41)$ & $13(5.33)$ & $11(4.51)$ & $3(1.23)$ & 21 (8.61) & 52 (21.31) & $41(16.80)$ \\
\hline 3 & 21 (36.21) & 0 & $1(1.72)$ & $22(37.93)$ & $3(5.17)$ & 7 (12.07) & 0 & $4(6.90)$ & 0 \\
\hline 4 & 0 & 0 & $0(0.00)$ & $23(85.19)$ & $3(11.11)$ & 0 & 0 & $1(3.70)$ & 0 \\
\hline 5 & $6(85.71)$ & 0 & 0 & 0 & 0 & $1(14.29)$ & 0 & 0 & 0 \\
\hline Sum up & $108(26.93)$ & 33 (8.23) & $2(0.50)$ & 73 (18.20) & 20 (4.99) & 24 (5.99) & $31(7.73)$ & $69(17.21)$ & $41(10.22)$ \\
\hline
\end{tabular}

${ }^{\star}$ This table presents the most severe injury sites related to the final AIS scores.

AIS, abbreviated injury scale. 
Table 4 The distribution of the injured in different damage and EF scale areas

\begin{tabular}{|c|c|c|c|c|}
\hline & Areas $\left(\mathrm{km}^{2}\right)$ & Number & Percentage (\%) & $\begin{array}{l}\text { Density } \\
\text { (number/km²) }\end{array}$ \\
\hline \multicolumn{5}{|l|}{ Damaged areas } \\
\hline Disaster affected area & 2457.18 & 37 & 9.23 & 0.02 \\
\hline Severe area & 118.13 & 64 & 15.96 & 0.54 \\
\hline Very severe area & 133.02 & 300 & 74.81 & 2.26 \\
\hline Sum up & 2708.33 & 401 & 100.00 & 0.15 \\
\hline \multicolumn{5}{|l|}{ EF scale } \\
\hline EFO & 129.74 & 20 & 8.10 & 0.15 \\
\hline EF1 & 84.19 & 139 & 56.28 & 1.65 \\
\hline EF2 & 27.61 & 40 & 16.19 & 1.45 \\
\hline EF3 & 13.66 & 33 & 13.36 & 2.42 \\
\hline EF4 & 5.66 & 15 & 6.07 & 2.65 \\
\hline Sum up & 260.86 & 247 & 100.00 & 0.95 \\
\hline
\end{tabular}

EF, Enhanced-Fujita.

tend to follow local demographics. For example, $44.4 \%$ of patients injured during the 2013 Lushan earthquake in China were middle-aged ( $31-50$ years) ${ }^{27}$ We note that this discrepancy may be related to disaster characteristics. Earthquakes are unpredictable and occur within a few minutes or seconds; therefore, both young adults and

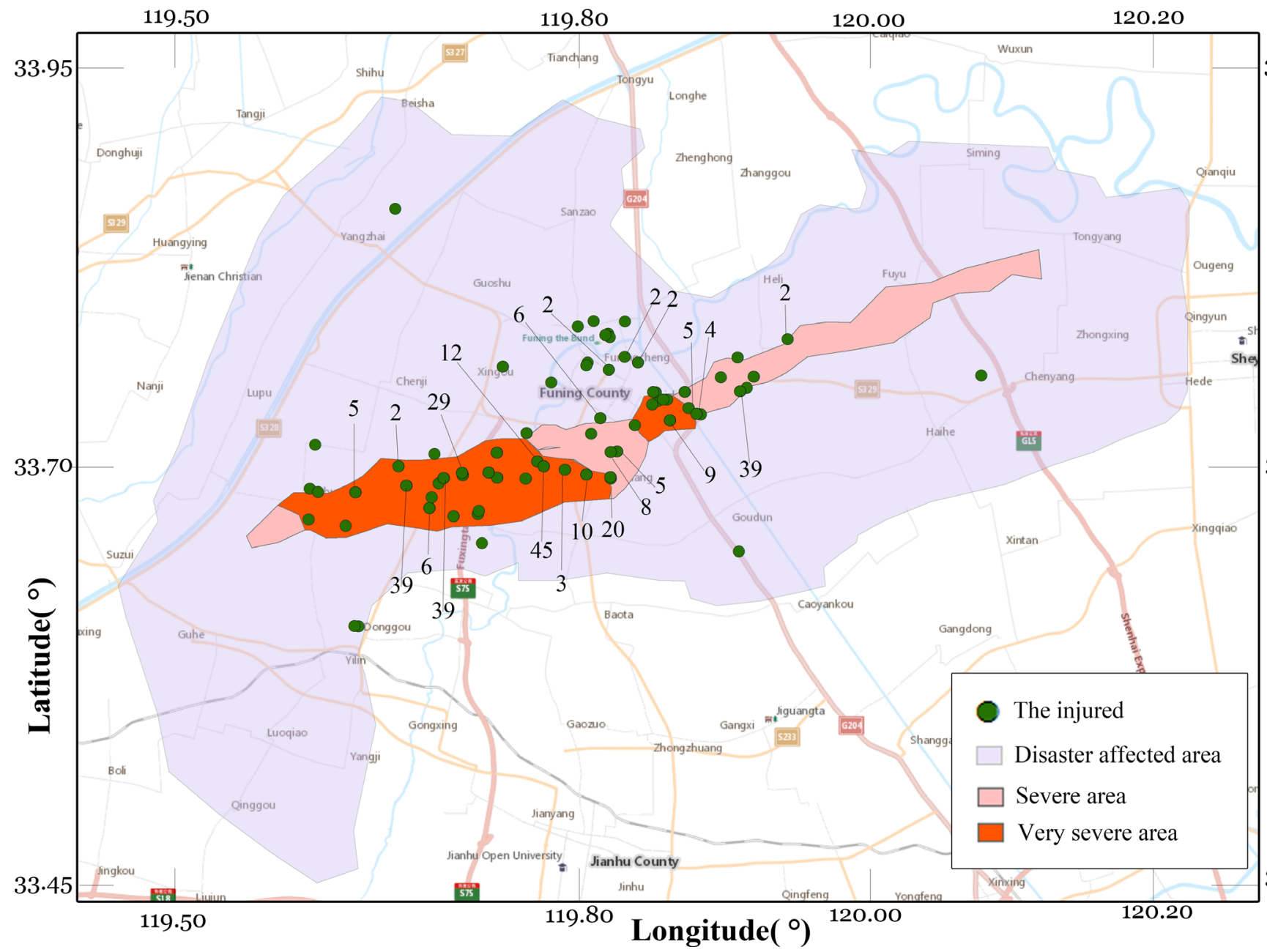

Figure 1 Distribution of the injured in different damage areas. When the locations of the wounded were extremely close, for the sake of clarity, they were aggregated into one point and labelled with patients' number involved. However, this did not alter the location of the wounded in different damage areas and related statistical analyses. 


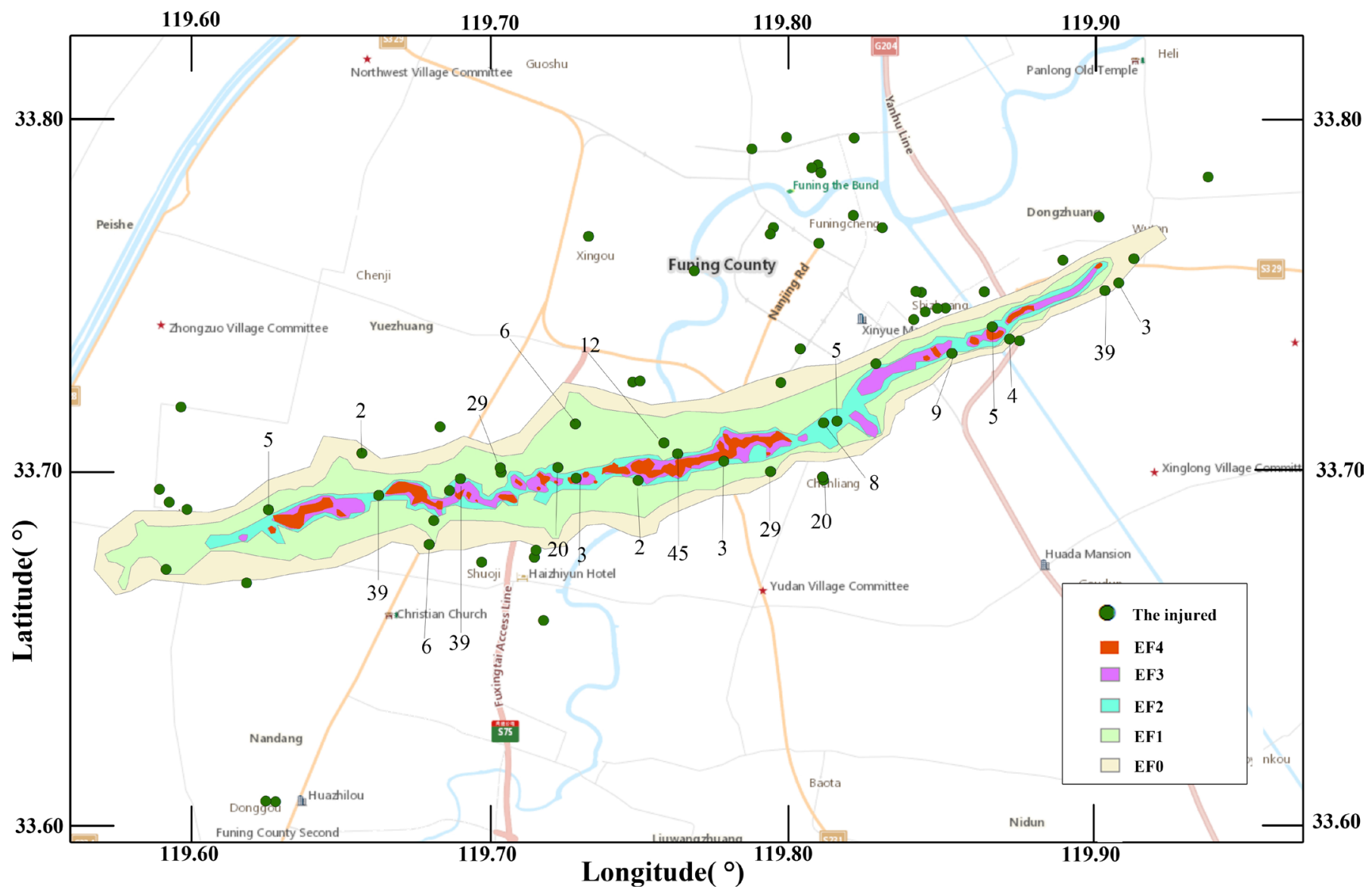

Figure 2 Distribution of the injured in different EF scale areas. When the locations of the wounded were extremely close, for the sake of clarity, they were aggregated into one point and labelled with patients' number involved. However, this did not alter the location of the wounded in different damage areas and related statistical analyses. EF, Enhanced-Fujita.

elderly people are unable to escape to safety. By contrast, tornadoes are of much longer duration, and warnings are generally provided. Therefore, teenagers and elderly individuals are more vulnerable to injury because they have fewer opportunities to receive these warnings and relocate to safety. Geographical characteristics may also play a role, as earthquakes are prone to occur in cities and counties (ie, populated areas). Some severe earthquakes have even occurred in big cities, where they have caused enormous damage and losses of life among all age groups. By contrast, tornadoes tend to occur in rural areas such as Chinese villages, where the population mainly comprises elderly people and adolescents because young adults have moved to cities for better

\begin{tabular}{|c|c|c|c|c|c|c|c|}
\hline & $\begin{array}{l}\mathrm{AIS}=1 \\
(\mathrm{n}, \%)\end{array}$ & $\begin{array}{l}\text { AIS }=2 \\
(n, \%)\end{array}$ & $\begin{array}{l}\mathrm{AIS}=3 \\
(\mathrm{n}, \%)\end{array}$ & $\begin{array}{l}\mathrm{AIS}=4 \\
(\mathrm{n}, \%)\end{array}$ & $\begin{array}{l}\text { AIS }=5 \\
(n, \%)\end{array}$ & $\begin{array}{l}\text { AIS }=6 \\
(n, \%)\end{array}$ & $P$ values \\
\hline Damaged areas & & & & & & & 0.131 \\
\hline Disaster affected area & $23(62.16)$ & $8(21.62)$ & $3(8.11)$ & $2(5.41)$ & $0(0.00)$ & $1(2.70)$ & \\
\hline Severe area & $33(51.56)$ & $8(12.50)$ & $14(21.88)$ & $8(12.50)$ & $1(1.56)$ & $0(0.00)$ & \\
\hline Very severe area & $188(62.67)$ & $46(15.33)$ & $41(13.67)$ & $17(5.67)$ & $6(2.00)$ & $2(0.67)$ & \\
\hline EF scale & & & & & & & 0.322 \\
\hline EF0 & $9(45.00)$ & $6(30.00)$ & $4(20.00)$ & $1(5.00)$ & $0(0.00)$ & $0(0.00)$ & \\
\hline EF1 & $92(66.19)$ & $18(12.95)$ & 17 (12.23) & $8(5.76)$ & $3(2.16)$ & $1(0.72)$ & \\
\hline EF2 & $26(65.00)$ & $7(17.50)$ & $5(12.50)$ & $1(2.50)$ & $1(2.50)$ & $0(0.00)$ & \\
\hline EF3 & $17(51.52)$ & $6(18.18)$ & $5(15.15)$ & $4(12.12)$ & $1(3.03)$ & $0(0.00)$ & \\
\hline EF4 & $10(66.67)$ & $3(20.00)$ & 2 (13.33) & $0(0.00)$ & $0(0.00)$ & $0(0.00)$ & \\
\hline
\end{tabular}

AIS, abbreviated injury scale; EF, Enhanced-Fujita. 
job opportunities. These aspects may be responsible for the dumbbell-shaped age distribution observed among tornado victims in this study.

\section{Injury site}

In our study population, the three most common injury sites were the head $(46.63 \%)$, limbs $(45.14 \%)$ and chest (22.69\%). By comparison, in the 2010 Yushu earthquake in China, the most common injury sites were the limbs $(48.1 \%)$, chest $(13.3 \%)$ and spine $(12.1 \%)$; head injuries accounted for only $10.1 \%$ of all injuries. ${ }^{28}$ Earthquake victims are most likely to be crushed by a heavy object, whereas tornado victims typically sustain head and limb injuries caused by flying objects and collapsing buildings. During the Alabama tornadoes of 2011, limb and pelvic injuries were most common, followed by head injuries, although the latter accounted for $46.5 \%$ of hospitalisations, $56.3 \%$ of intense care unit admissions and $71.4 \%$ of deaths. ${ }^{8}$ Another study found that head injury was the greatest cause of tornado-related deaths in the USA. ${ }^{7}$ In our study, head injury was the most frequent cause of an AIS score $\geq 5$ and the cause of the only hospital death. Given the significant risk of head injury, researchers have recommended the use of a helmet to protect the head during a tornado, ${ }^{29}{ }^{30}$ and medical rescue teams aiming to reduce high mortality rates should prioritise patients with head injuries, especially in cases with concomitant hypothermia, hyperglycaemia and coagulation disorders. ${ }^{31}{ }^{32}$

\section{Injury type}

In our study, the three most common injury types were skin and soft-tissue injuries $(90.77 \%)$, fractures $(38.90 \%)$ and organ damage $(19.70 \%)$. The first type is commonly caused by heavy objects rendered airborne by a tornado. ${ }^{3033} 34$ Fractures have been attributed to building collapse, collisions with heavy objects and various other events. Consistent with previous studies, we found that organ damage occurs frequently during a tornado. ${ }^{35}$ The strong winds associated with a tornado can cause people to fall or even to be lifted and subsequently dropped, which can cause serious organ damage and potentially fatal internal bleeding. However, organ damage is more difficult to diagnose, compared with a skin injury. Therefore, medical rescuers should attend more closely to victims who remain quiet but exhibit signs of pain.

We additionally found that $5.24 \%$ of injury victims developed bacterial infections, which were likely caused by the chaotic environment. ${ }^{30} 33343637$ Recommendations suggest that to prevent gangrene and sepsis during the early stage, medical rescuers should perform extensive surgical debridement rather than wound suturing too early. ${ }^{7}$ Interestingly, fractures and infections were also observed frequently among the victims of explosions at the Boston Marathon in 2013 and Tianjin Port in 2015, which suggests that tornado forces share some qualities with explosions. 3839

\section{Injury severity}

According to the AIS scores, ${ }^{23} 2460.85 \%$ of victims in our study sustained minor injuries, while $15.46 \%$, $14.46 \%, 6.73 \%, 1.75 \%$ and $0.75 \%$ sustained moderate, severe but non-life-threatening, severe and life-threatening, critical injury and fatal injuries, respectively. A previous report found that $89 \%$ of all injuries associated with the Alabama tornadoes of 2011 were minor, $6 \%$ were moderate and only $5 \%$ were severe. ${ }^{8}$ The increased proportion of severely injured victims in our study may be related to the lack of tornado protection awareness and ability in China.

Notably, our analysis of different damage and EF-scale areas found no related differences in the victims' AIS scores. In other words, areas of severe destruction had similar percentages of severely injured victims as those in areas of minor destruction and low wind speeds. Because the "Trauma Golden Hour Policy' ${ }^{40}$ and 'Brass 10 min',1 play a vitally important role in saving severely injured patients, we strongly recommended that similar attention be given to severely injured victims, regardless of the level of damage and EF-scale. In other words, all tornado-affected areas deserve to receive the same quality of medical care at the same time.

\section{Injury densities in different areas}

Although the distributions of injury severity were similar among areas with different damage levels and EF-scale ratings, the densities and numbers of injured patients differed. Specifically, the density of injured patients increased with the severity of tornado-related damage in the area, which was mainly related to the wind speed and building destruction. As the wind speeds range from EF1 at the edge of a tornado to EF4 at the centre, ${ }^{15}$ we recommend that different quantities of emergency medical personnel be deployed to different disaster areas. Specifically, larger numbers of medical personnel should be deployed to severely affected areas, which contain more victims and higher densities of injured patients. We therefore recommend that the 'same quality and different quantity' policy should be implemented during tornado-related emergency medical rescues.

\section{Limitations}

This study had two limitations of note. First, we only collected the medical records of 451 injured patients. However, our study included both a first-line hospital (Funing County People's Hospital) and two rearline hospitals (Jianhu County People's Hospital and Yancheng Third People's Hospital), which collectively treated $53.31 \%$ of all 846 injured patients. Therefore, our dataset is considered representative of the target population. Second, this study could not evaluate the geographical distribution of deaths because of limited information. 


\section{CONCLUSION}

To sum up, this study is the first to describe the pattern and spectrum of tornado-related injuries in China, and the first to use the GIS to analyse the characteristics of injury locations according to different damage levels and EF-scale areas. Notably, we observed a dumbbell-shaped age distribution among the victims of a particular tornado in China. Our further findings of regional differences in the density but not severity of injury have led us to recommend the application of the 'same quality and different quantity' strategy to tornado-related emergency medical rescue scenarios. Additionally, the high incidence of head injuries and associated high fatality rate have led us to recommend that people, and particularly children, wear helmets as they shelter or evacuate from a tornado. We expect that our findings will be very helpful to the planning of emergency medical rescue efforts and the appraisal of potential medical demands following tornadoes.

Acknowledgements We would like to thank the three hospitals in Yancheng for providing these medical records of tornado patients. We would like to thank Professor Zhiyong Meng of Peking University for her kind assistance with the EF isopleths of the 23 June 2016 Yancheng tornado. We would also like to thank Editage (http://www.editage.cn) for providing English language editing.

Contributors QD, YL, CX, PK, JD and LZ discussed and developed the hypothesis for this study. QD and YL abstracted data from medical records. QD and CX performed all analyses. All authors were involved in the interpretation and discussion of results. QD and YL wrote the first draft of this paper, which was reviewed by LZ. All authors agreed on the final draft of this study. LZ is the study guarantor

Funding This research was funded by the National Natural Science Foundation of China (LZ, grants 71774167, 71233008 and 91224005; PK, grant 71603271), the Special Innovation Project of National Defence Science and Technology (LZ, grant 003004), the Military Medical Innovation Project of the 13th Five-Year Plan of the People's Liberation Army (LZ, grant 17CXZ001), the Major Project of the 12th Five-Year Plan of the People's Liberation Army (LZ, grant AWS12J002) and the Joint Research Project in Major Disease at the Shanghai Health Service (LZ, grant 2013ZYJB0006).

Competing interests None declared.

Patient consent Obtained.

Ethics approval Medical Ethics Committee of the Second Military Medical University.

Provenance and peer review Not commissioned; externally peer reviewed.

Data sharing statement № additional data are available.

Open access This is an open access article distributed in accordance with the Creative Commons Attribution Non Commercial (CC BY-NC 4.0) license, which permits others to distribute, remix, adapt, build upon this work non-commercially, and license their derivative works on different terms, provided the original work is properly cited and the use is non-commercial. See: http://creativecommons.org/ licenses/by-nc/4.0/

(C) Article author(s) (or their employer(s) unless otherwise stated in the text of the article) 2018. All rights reserved. No commercial use is permitted unless otherwise expressly granted.

\section{REFERENCES}

1. Ashley WS. Spatial and temporal analysis of Tornado fatalities in the United States: 1880-2005. Weather Forecast 2007;22:1214-28.

2. Fricker T, Elsner JB, Mesev V, et al. A dasymetric method to spatially apportion tornado casualty counts. Geomatics, Natural Hazards and Risk 2017;8:1768-82.
3. Lyu H-M, Wang G-F, Cheng W-C, et al. Tornado hazards on June 23 in Jiangsu Province, China: preliminary investigation and analysis. Nat Hazards 2017;85:597-604.

4. Jia H, Pan D. Tornado disaster impacts and management: learning from the 2016 tornado catastrophe in Jiangsu Province, China. Nat Hazards 2017;89:457-71.

5. Wang K, Zhong S, Wang X, et al. Assessment of the public health risks and impact of a Tornado in funing, China, 23 June 2016: a retrospective analysis. Int J Environ Res Public Health 2017;14:1201.

6. Dapeng H, Shanshan Z, Ge G, et al. Disaster characteristics of tornadoes over China during the past 30 years. Torrential Rain and Disaster 2016;35:97-101.

7. Bohonos JJ, Hogan DE. The medical impact of tornadoes in North America. J Emerg Med 1999;17:67-73.

8. Niederkrotenthaler T, Parker EM, Ovalle F, et al. Injuries and posttraumatic stress following historic tornados: Alabama, April 2011. PLoS One 2013;8:e83038.

9. Kanter RK. The 2011 Tuscaloosa tornado: integration of pediatric disaster services into regional systems of care. J Pediatr 2012;161:526-30.

10. Salottolo K, Settell A, Uribe P, et al. The impact of the AIS 2005 revision on injury severity scores and clinical outcome measures. Injury 2009;40:999-1003.

11. Bell N, Schuurman N. GIS and injury prevention and control: history, challenges, and opportunities. Int J Environ Res Public Health 2010;7:1002-17.

12. Waring S, Zakos-Feliberti A, Wood R, et al. The utility of geographic information systems (GIS) in rapid epidemiological assessments following weather-related disasters: methodological issues based on the Tropical Storm Allison Experience. Int $J$ Hyg Environ Health 2005;208(1-2):109-16.

13. Peek-Asa C, Ramirez MR, Shoaf K, et al. GIS mapping of earthquake-related deaths and hospital admissions from the 1994 Northridge, California, Earthquake. Ann Epidemiol 2000;10:5-13.

14. Curtis JW, Curtis A, Upperman JS. Using a geographic information system (GIS) to assess pediatric surge potential after an earthquake. Disaster Med Public Health Prep 2012;6:163-9.

15. Kanti Paul B, Stimers M. Spatial analyses of the 2011 joplin tornado mortality: deaths by interpolated damage zones and location of victims. Weather Clim Soc 2014;6:161-74.

16. Centers for Disease Control and Prevention (CDC). Tornado-related fatalities-five states, Southeastern United States, April 25-28, 2011. MMWR Morb Mortal Wkly Rep 2012;61:529-33.

17. Simmons KM, Sutter D. Economic and societal impacts of tornadoes : University of Chicago Press Economics Books, 2011:56: 412-5.

18. Fricker T, Elsner JB, Jagger TH. Population and energy elasticity of tornado casualties. Geophys Res Lett 2017;44:3941-9.

19. Center, W. S.a. E. A recommendation for an Enhanced Fujita Scale 2013:20132013. cited.

20. Curtis A, Fagan WF. Capturing Damage Assessment with a Spatial Video: An Example of a Building and Street-Scale Analysis of Tornado-Related Mortality in Joplin, Missouri, 2011. Ann Assoc Am Geogr 2013;103:1522-38.

21. Shen G, Hwang SN. A spatial risk analysis of tornadoinduced human injuries and fatalities in the USA. Nat Hazards 2015;77:1223-42.

22. Lim J, Loveridge S, Shupp R, et al. Double danger in the double wide: Dimensions of poverty, housing quality and tornado impacts. Reg Sci Urban Econ 2017;65:1-15.

23. Rating the severity of tissue damage. I. The abbreviated scale. JAMA 1971;215:277-80.

24. Gennarelli TA, Wodzin, AIS E. a contemporary injury scale. Injury 2005;37:1083-91.

25. Palmer CS, Niggemeyer LE, Charman D. Double coding and mapping using Abbreviated Injury Scale 1998 and 2005: identifying issues for trauma data. Injury 2010;41:948-54.

26. Daley WR, Brown S, Archer P, et al. Risk of tornado-related death and injury in Oklahoma, May 3, 1999. Am J Epidemiol 2005;161:1144-50.

27. Kang P, Tang B, Liu Y, et al. Medical Efforts and Injury Patterns of Military Hospital Patients Following the 2013 Lushan Earthquake in China: A Retrospective Study. Int J Environ Res Public Health 2015;12:10723-38.

28. Kang $P$, Zhang L, Liang $W$, et al. Medical evacuation management and clinical characteristics of 3,255 inpatients after the 2010 Yushu earthquake in China. J Trauma Acute Care Surg 2012;72:1626-33.

29. Brenner SA, Noji EK. Tornado injuries related to housing in the Plainfield tornado. Int J Epidemiol 1995;24:144-9.

30. Rosenfield AL, McQueen DA, Lucas GL. Orthopedic injuries from the Andover, Kansas, tornado. J Trauma 1994;36:676-9. 
31. Tude Melo JR, Di Rocco F, Blanot S, et al. Mortality in children with severe head trauma: predictive factors and proposal for a new predictive scale. Neurosurgery 2010;67:1542-7.

32. Franko J, Kish KJ, O'Connell BG, et al. Advanced age and preinjury warfarin anticoagulation increase the risk of mortality after head trauma. J Trauma 2006;61:107-10.

33. Marr J. Kalamazoo medics say 'fantastic'! to health personnel response after tornadoes. Mich Med 1980;79:374-6.

34. Leibovich M. The December 2, 1982 tornado of Saline and Pulaski counties: implications for injury prevention. J Ark Med Soc 1983;80:98-102.

35. Ivy $\mathrm{JH}$. Infections encountered in tornado and automobile accident victims. J Indiana State Med Assoc 1968;61:1657-61.
36. Mandelbaum I, Nahrwold D, Boyer DW. Management of tornado casualties. J Trauma 1966;6:353-61.

37. Morris BA, Armstrong TM. Medical response to a natural disaster: the Barrie tornado. CMAJ 1986;134:767-9.

38. Kim PS, Malin E, Kirkham JC, et al. The Boston marathon bombings: the early plastic surgery experience of one Boston hospital. Plast Reconstr Surg 2013;132:1351-63.

39. Zhang JJ, Wang TB, Fan D, et al. Medical Response to the Tianjin Explosions: Lessons Learned. Disaster Med Public Health Prep 2017:1-4.

40. Howard JT, Kotwal RS, Santos AR, et al. Re-examination of a Battlefield Trauma Golden Hour Policy. J Trauma Acute Care Surg 2017.

41. Shomaker D. Survival, respect and equality. Br J Nurs 1994;3:792-3. 